\title{
História da Psicologia e contexto sociocultural - pesquisas contemporâneas, novas abordagens
}

\section{History of Psychology and sociocultural context - contemporany researches, new approaches}

\section{Historia de la psicología y el contexto sociocultural - investigaciones contemporáneas, nuevos enfoques}

\section{Cecília Andrade Antipoff*}

Universidade Federal de Minas Gerais - UFMG, Belo Horizonte, Minas Gerais, Brasil

Lourenço, E., Assis, R. M., Campos, R. H. F. (2012). História da Psicologia e contexto sociocultural - pesquisas contemporâneas, novas abordagens. Belo Horizonte: PUC Minas.

Os estudos de História da Psicologia no Brasil vêm se intensificando e ganhando força na contemporaneidade. Prova disso é a obra recentemente lançada, intitulada História da psicologia e contexto sociocultural - pesquisas contemporâneas, novas abordagens, onde os autores apresentam um objetivo em comum: aprimorar a qualidade das pesquisas nesta área.

Os dezoito artigos constantes da obra são o resultado de trabalhos apresentados no XXVIII Encontro Anual Helena Antipoff e IX Encontro Interinstitucional de pesquisadores em psicologia, realizado em 2010 na Faculdade de Educação da UFMG, cujo tema foi: Psicologia, Psicanálise e Educação na cultura contemporânea.

A partir de uma diversidade de temas abordados, tais como: a circulação e transformação do conhecimento e da prática científica da Psicologia; a conexão entre a Psicologia e o contexto sociocultural brasileiro; a relação entre a pedagogia e as práticas psicológicas, entre outros, fica evidente a significativa importância da obra para os estudos em História da Psicologia. Ao longo da leitura percebe-se a busca por uma interlocução entre uma perspectiva histórica das áreas da Psicologia e da Educação e os desafios impostos tanto no entendimento quanto nas práticas contemporâneas.

Os artigos foram cuidadosamente redigidos, fundamentados em literatura pertinente, sendo que, em muitos casos, resultam de pesquisas acadêmicas de Mestrado e Doutorado em andamento ou já 
concluídas. O livro está organizado em três partes: A psicologia em construção: ciência, circulação de saberes e suas relações com a cultura; Configurações dos saberes e das práticas em psicologia no Brasil e Pesquisas em história da psicologia, da psicanálise e da educação.

Na primeira parte, intitulada A Psicologia em construção: ciência, circulação de saberes e suas relações com a cultura, os artigos trazem contribuições relevantes para as pesquisas em História da Psicologia apontando algumas tendências do estudo histórico da psicologia como, por exemplo, o entendimento do processo de circulação e recepção de um conhecimento científico, como também, a importância de se entender este processo de recepção como uma relação direta com as condições socioculturais do contexto em questão.

Ênfase é dada aos aspectos culturais na construção do conhecimento científico, buscando uma interlocução da Psicologia com os saberes do cotidiano e do senso comum, além de algumas áreas do conhecimento, tais como a filosofia e as artes. Pickren, por exemplo, aborda questões referentes à circulação e transformação do conhecimento e da prática científica, especificamente no que diz respeito ao conhecimento da Psicologia. Enfatiza a postura ativa dos seres humanos neste processo de receber conhecimentos transformando-os de forma a adequá-los às suas diferentes situações e realidades. Uma das questões formuladas refere-se ao que acontece neste processo de transmissão de práticas e conhecimentos, especialmente nos lugares onde os contrastes e diferenças culturais mostram-se significativos.

Tal colocação vai ao encontro ao apontado por Massimi que, em seu texto, busca uma conexão entre a Psicologia e a Cultura (mais especificamente, o contexto sociocultural brasileiro em sua complexidade de estratificações culturais). A autora afirma que o contexto sociocultural brasileiro é considerado como um universo formado por sujeitos culturais diferenciados que, pela marca da diferença, foram submetidos a formas distintas de historicidade. Sendo assim, foram sendo construídas distintas modalidades de elaborações da experiência psicológica. E é a partir desta complexidade que a inscrição da História dos Saberes Psicológicos é colocada em destaque. Sob este ponto de vista, Massimi aponta que as tradições de pesquisas são marcadas pelas culturas, especificamente no que diz respeito aos padrões de raciocínio, crenças, campo de interesses, necessidades e formas de organização social.

Corroborando Pickren e Massimi, Rutherford, com o exemplo da teoria da aprendizagem de Skinner através da proposta de instrução programada, desenvolve a questão de que tanto as ideias quanto as práticas científicas expressam preocupações sociais e estão em 
constante interação com o contexto sociocultural no qual estas são desenvolvidas. Ao longo do artigo, a autora traz uma contextualização histórico-cultural americana relacionando 0 momento vivenciado pelo país tanto com a receptividade e aceitação, quanto pelo questionamento e rejeição da máquina de ensinar e da proposta de um ensino programado que a amparava.

Outro conceito de grande importância para a compreensão da História da Psicologia, trazido por Pikcren nesta primeira parte do livro, é a ideia de "indigenização" da Psicologia. Para o autor, o processo de indigenização do conhecimento (ou de tornar um conhecimento local ou nativo) representa uma perspectiva humana que acontece não só quando se diz respeito ao conhecimento científico, mas, também, no que se refere às diferentes práticas humanas.

Para contextualizar seus argumentos, Pickren traz uma abordagem histórica da Psicologia, marcada por um domínio americano no século $X X$, quadro este que se modifica com o advento do processo de globalização, a partir do qual a Psicologia é marcada pelos diferentes países e culturas, pelos quais perpassa. Em seguida, o autor propõe um modelo de transmissão de conhecimento baseado na concepção de "Centro" - "periferia", indicando que, em um primeiro momento, os conhecimentos psicológicos considerados científicos advinham deste modelo, sendo que a circulação das informações e dos conhecimentos vinham, especificamente, dos grandes centros (como EUA, Europa) para as periferias (como a Índia, por exemplo). Pickren aponta uma tendência mais atual na qual este modelo não é o único proposto. A perspectiva atual busca o entendimento das histórias locais, das "Psicologias" constituídas e construídas nas periferias a partir dos conhecimentos advindos dos grandes centros.

Portanto, é tangível a compreensão destes conceitos para a compreensão da transformação científica e cultural, além da sensibilização para as novas possibilidades de conhecimento que são criadas nas zonas de contatos culturais.

Outro aspecto ressaltado nesta primeira parte e que merece destaque é a proposta trazida por Araujo: buscar o contexto (ou o todo) para se compreender determinado aspecto histórico (considerado como a parte), mais especificamente no que diz respeito aos estudos sobre a Psicologia. O autor enfatiza a importância dos estudos da História da Psicologia como forma de problematizar o presente. Assim como Araujo, Massimi chama atenção para a necessidade de uma cultura preservar seu passado, pois acredita que é no passado que estão as raízes não só da cultura em si, mas, também, de suas tradições de pesquisas.

Partindo também deste pressuposto, Santos e Portugal, ao dizer sobre a História da Psicologia e seu entendimento, apontam para a necessidade de se compreender outro aspecto da psicologia de Wundt 
que não apenas o seu viés experimentalista. Destacam os aspectos sociais e sócio-históricos presentes na obra deste pesquisador. Citam, por exemplo, a Völkerpsychologie, ou a psicologia dos povos, para a qual Wundt dedicou grande parte de sua obra. Os autores utilizam o caso dos estudos em psicologia da percepção para demonstrar o privilégio positivista na construção da História da Psicologia.

A segunda parte da obra, denominada Configurações dos saberes e das práticas em psicologia no Brasil presenteia o leitor com resultados de pesquisas, além de relatos referentes a temas que buscam uma articulação com a contemporaneidade e que se referem, especialmente, ao entendimento da constituição da Psicologia no contexto brasileiro.

Yamamoto, Costa, Seixas e Amorim, por exemplo, trazem uma contribuição para o entendimento da profissão do psicólogo no Brasil através de uma pesquisa realizada entre os anos de 2008 e 2009, cujo objetivo foi o de organizar e sistematizar a literatura científica publicada no Brasil sobre este campo de atuação. Os autores entenderam que, desde a regulamentação da profissão do psicólogo no Brasil, em 1962, muitos foram os estudos que buscaram refletir sobre a atuação deste profissional, mas, apesar disto, verificaram que estudos com este tema, não se mostraram ser a preocupação central dos pesquisadores, o que denota que a profissão de psicólogo no país, enquanto objeto de estudo científico, tem um caráter complementar ou temporário.

Lemos e Cirino, através da análise de regulamentações brasileiras da Educação e da Psicologia, vigentes entre os anos de 1962 e 2008, fundamentados na proposta metodológica da nova história, buscam estabelecer uma relação entre estes aportes legais e a construção da identidade do licenciado em Psicologia a partir de um referencial sócio-histórico.

Os autores apontam alguns aspectos de significativa importância para a compreensão da identidade deste profissional, articulando os resultados obtidos com a realidade sócio-histórica vigente. Entre as constatações, estão: a divergência entre o que é proposto legalmente ao licenciado de psicologia (como, por exemplo, o direito de atuar como docente) e aquilo que acontece, de fato, na sua prática profissional; a defasagem em termos de informações sobre o tema não somente para a sociedade acadêmica, mas, também, para a sociedade civil, além da constatação de que os cursos de Psicologia atuais não estão de acordo com as novas diretrizes, que vêm propor a sua integração com as licenciaturas.

Além disso, ressaltam a defasagem da legislação referente à Psicologia, que é entendida como estando descontextualizada com a atual realidade política, econômica e social. Destacam, portanto, a necessidade de um questionamento e de uma reformulação destes aportes legais. 
Para compreender as práticas de Psicologia no contexto brasileiro, Gonçalves, Jeison de Miranda e Miranda e Cirino, apontam sobe a importância de estudar um laboratório a partir de seus instrumentos como uma forma de favorecer a análise das apropriações deste laboratório em relação às demandas sociais e históricas nas quais se deram essas práticas.

Parte-se do pressuposto de que os fatos científicos, assim como os instrumentos que os produzem, estão relacionados às concepções filosóficas e científicas vigentes.

Ao longo do artigo, apresentam uma reflexão histórica sobre a apropriação da caixa de Skinner no Brasil, mais especificamente, no Laboratório de Análise do Comportamento da Universidade de São Paulo (USP), na década de 1960.

Diferentemente do que ocorreu nos Estados Unidos, os autores apontaram que, no Brasil, a partir de todo um contexto sóciohistórico, a caixa de Skinner foi apropriada pelos brasileiros, de forma prioritariamente didática.

Também nesta segunda parte, Penzim e Rogrigues, Silva, Oliveira e Belém, se debruçaram sobre a interessante tarefa de relatar a visita de alguns estrangeiros ao Brasil, dando ênfase às contribuições e influências que estas marcantes presenças trouxeram no que se refere à construção de novas práticas no campo de atuação da Psicologia.

Dentre os intelectuais e cientistas apresentados nos artigos, citamse: Michel Foucault, que esteve em Belo Horizonte na década de 1970 e Basaglia. Embora tivessem focos de trabalho diferentes, suas posturas nas visitas ao Brasil foram semelhantes em alguns aspectos. Tanto a presença de Foucault com sua "postura-intervenção", quanto Basaglia com a estratégia de proporcionar um clima de divulgação das condições dos doentes mentais, mobilizando a opinião das pessoas quanto a esta questão, fizeram com que os encontros dos quais estiveram presentes, se transformassem em espaço de trocas de experiências entre profissionais, possibilitando o questionamento e o repensar de práticas cotidianas.

Já na terceira e última parte do livro, denominada Pesquisas em história da psicologia, da psicanálise e da educação são apresentados artigos que objetivam apontar diálogos entre as ciências psicológicas e as práticas pedagógicas. Esta escolha traz uma contribuição inestimável para os pesquisadores que estudam aspectos históricos da Psicologia e da Educação como uma forma de acrescentar novos dados sobre estas áreas de atuação, aperfeiçoando a compreensão do que hoje se apresenta nestes contextos.

O que pode ser depreendido nesta parte da obra é que os artigos contam, em diferentes aspectos e contextos, como a pedagogia abriu espaço para a constituição da Psicologia científica enquanto campo de atuação no Brasil. Além disso, apontam a Psicanálise como sendo 
relevante para uma melhor compreensão sobre o universo infantil, trazendo as diferentes formas de aprendizagem e a busca por novos métodos educacionais.

Dentro deste contexto, Pacheco apresenta uma perspectiva histórica da prática dos jesuítas voltando às origens da Educação, a fim de obter um melhor entendimento sobre o campo de trabalho da Psicologia e da Educação que, segundo o autor, vem enfrentando uma crise e constantes buscas de respostas na contemporaneidade.

Já Antunes, apresenta a psicologia do desenvolvimento montessoriana, enfatizando algumas formulações referentes à criança e seu psiquismo. O sistema montessoriano de educação é apresentado, podendo ser vislumbrado a partir das concepções humanista, interacionista e psicanalítica.

O artigo traz uma relação do sistema Montessori com a Psicologia, sendo esta apontada como a principal contribuição científica à educação, uma vez que produziu um vasto conhecimento sobre como a criança se desenvolve, através de um método observacional.

A criança, sob este viés, não era vista ou entendida como a miniatura de um adulto, mas como um ser que nasce com potencialidades que necessitam de um ambiente propício e adequado para que seu desenvolvimento se dê de forma plena e equilibrada. Além disso, existia a crença na necessidade de que os adultos entendessem como a criança se desenvolve para atuarem de forma efetiva, sem direcionar ou reprimir, mas dando liberdade para que esta pudesse dar vazão às suas potencialidades, o que caracteriza uma educação centrada na criança.

Também nesta parte da obra, o leitor pode encontrar uma importante contribuição de Ohayon, que faz uma exposição da Psicanálise e da Educação no contexto francês.

Mota e Silva buscam entender qual o lugar da Psicanálise no mundo atual. Através de um resgate histórico do entendimento do processo de subjetivação (passando pela Idade Média, Renascimento até a Modernidade), apontam para uma modificação no papel da função paterna (entendida como representação simbólica de uma autoridade capaz de transmitir os ideais de uma cultura).

Uma breve relação entre a Psicanálise e a Educação é proposta, trazendo à tona o professor e sua função de transmissão de conhecimento e de cultura.

As autoras constatam a necessidade de uma reconfiguração do papel do analista e da psicanálise, tendo em vista as modificações da função paterna e dos sintomas da contemporaneidade.

Gebrim faz uma análise das contribuições da Psicologia para a Pedagogia nova que se instaurou no Brasil no século XX, destacando a Psicologia Experimental como sendo propiciadora de significativas contribuições para responder questões e problemas advindos do ensino público através de um estudo científico da criança. Desse 
modo, a aprendizagem de cada criança com seus interesses, passam a ser o foco das preocupações, ficando evidente a inquestionável contribuição que a Escola Nova trouxe para o campo educacional brasileiro.

Através de uma interlocução com a historiografia da psicologia brasileira, Rodrigues e Araujo também presenteiam o leitor com uma reflexão a respeito da história da Psicologia em Goiás a partir da influência dos preceitos escolanovistas advindos dos estados de São Paulo e Minas Gerais (com Helena Antipoff) que marcaram não apenas o movimento de renovação pedagógica no sistema educacional goiano, mas também, os cursos de formação de professores e os discursos de ordem política.

Sob um viés também sócio-histórico e cultural, Carrijo, inspirada na obra de Àries, analisa imagens sobre a infância na contemporaneidade. A partir da análise das imagens, a autora considera que a infância aparece psicopatologizada e pautada numa lógica mercadológica e de consumo, cabendo às práticas da Psicologia responder às demandas contemporâneas de entendimento do mundo infantil.

Neste artigo, aparece uma crítica à medicalização da infância, apontando para as recorrentes prescrições medicamentosas visando à modificação do funcionamento do corpo biológico da criança (criança esta vista e tratada de acordo com as suas (dis)funções cognitivas), desconsiderando o todo social que ampara este corpo infantil em relação e em funcionamento.

Finalizando a obra, Assunção, Assis e Campos, amparadas pela teoria das Representações Sociais, analisam como se deu a educação dos corpos infantis na revista Pais \& Filhos entre os anos de 1968 a 1977. O objetivo das autoras foi compreender qual o ideal de infância propagado e legitimado por esta revista na época acima delimitada.

As autoras apontam que o entendimento das representações sociais sobre a infância mostram-se importantes uma vez que estas representações são construções humanas, discursivas e que apresentam consequências constitutivas no sujeito em formação.

As autoras constataram que as representações sociais dos corpos infantis na revista e no período analisados, indicam um modelo de criança magra, branca, limpa, que se veste com roupas descritas como modernas e alegres, além de serem entendidos e marcados por um ponto de vista dual: sadio versus saudável; corpos normais versus anormais.

Finalizando esta apresentação crítica, a leitura deste livro é recomendada não apenas para aqueles que se interessam pelos estudos em história da psicologia, mas, também, para aqueles que buscam uma melhor compreensão das práticas psicológicas e educacionais na contemporaneidade. 


\section{Endereço para correspondência}

Faculdade de Educação da UFMG

Av. Antônio Carlos, 6627, Pampulha, CEP 31270-901, Belo Horizonte - MG, Brasil

Endereço eletrônico: cecilia.antipoff@gmail.com

Recebido em: 03/09/2013

Reformulado em: 19/02/2014

Aceito para publicação em: 26/02/2014

Notas

* Doutoranda da Faculdade de Educação - UFMG / Professora do Centro Universitário UNA, Belo Horizonte - Minas Gerais / Brasil. 